\title{
Recommendations for the prevention of breast cancer in shift workers
}

\author{
Kneginja Richter • Jens Acker • Nikola Kamcev • \\ Stojan Bajraktarov • Anja Piehl • Guenter Niklewski
}

Received: 20 May 2011 / Accepted: 5 August 2011 / Published online: 23 December 2011

(C) European Association for Predictive, Preventive and Personalised Medicine 2011

\begin{abstract}
The functioning of the human body is regulated by the rhythmical change between rest and activity. The SCN (suprachiasmatic nucleus) is responsible for the central control of the biorhythm and the genetic prediction of the individual chronotype, whereas peripheral time cues such as light, social contacts and times of meals modulate the rhythmical activity of the body. Shift workers suffer from a disruption of the sleep-wake rhythm, insomnia and a lack of melatonin. These factors might trigger the development of breast cancer in female shift workers. The growing amount of data which indicate the high risk of breast cancer in female shift workers demonstrates the need for the implementation of prevention strategies against insomnia in shift workers. These strategies include regular sleep education courses on the prevention of sleep disorders in companies. The individual chronotype could be an important predictor for the adaptability to shift work.
\end{abstract}

\author{
K. Richter $(\bowtie) \cdot$ J. Acker $\cdot$ A. Piehl \\ Center for sleep medicine, Klinikum Nürnberg Nord, \\ Haus 34, Prof.-Ernst-Nathan-Straße 1, \\ 90419 Nürnberg, Germany \\ e-mail: richter@epmanet.eu \\ N. Kamcev \\ Medical Faculty, University Goce Delcev, \\ Stip, Macedonia \\ S. Bajraktarov \\ Clinic for psychiatry, University Kiril and Methodi, \\ Skopje, Macedonia \\ G. Niklewski \\ Clinic for Psychiatry and Psychotherapy, \\ Klinikum Nürnberg Nord, \\ Haus 31/2, Prof.-Ernst-Nathan-Straße 1, \\ 90419 Nürnberg, Germany
}

Keywords Shift work · Sleep-wake activity $\cdot$ Sleep disorder - Insomnia · Breast cancer - Prevention - Prediction . Personalised medicine $\cdot$ Circadian activity

\section{Shiftwork and breast cancer}

Several studies have demonstrated a correlation between night work and an increased risk of breast cancer [1-4]. Mostly, women aged between 30 and 45 get breast cancer. So far, studies have most frequently examined nurses and air stewardesses [4]. In 2007, the International Agency for Research on Cancer (IARC) classified shift work with circadian disruption as probably carcinogenic to humans (Group II A Carcinoma). This classification as probably carcinogenic results from the fact that there is only limited evidence in humans but sufficient evidence from laboratory studies. IARC is an institution of WHO. Shift work thus leads to a risk classification which puts it on the same level as UV radiation and Benzo(a)pyrene and acrylamide. In 2008, working conditions on shift were recognised as the cause of breast cancer in 38 night shift workers in Denmark and they were granted compensation. At present, the necessary preconditions for a comparable recognition of occupational diseases do not exist in Germany because the scientific basis is still lacking. The present paper mainly cites studies which cover large numbers of shift workers and staff working at night. Even though, at present, it has by no means been confirmed that shift work contributes to the development of cancer, the authors nevertheless recommend prevention strategies such as organising shift work rotas in a health-conducive way by taking into account current findings from occupational medicine, chronobiology and occupational sciences [5]. 


\section{Pathophysiological mechanisms}

Many factors are involved in the pathophysiology of breast cancer in shift workers: light exposure, production of melatonin, cortisol, estradiol, sleep deprivation, circadian disruption, chronotype as well as some behavioural habits (Fig. 1).

\section{Light exposure and melatonin}

Light exposure at night can heighten the risk for breast cancer because of the decreased release of melatonin which, in turn, promotes the release of estrogen. The present study examines whether light exposure increases the risk for breast cancer. Included in the study were 813 female patients aged between 20 and 74. The patients were questioned about their sleeping habits during the last 10 years, about the number of times they woke up at night, whether they switched on the light after waking up and whether they worked in shifts. Moreover they were questioned about the degree of darkness in their bedrooms [6].

A positive correlation was found between breast cancer and shift work for over 10 years. Moreover, a correlation was found between breast cancer and, among other things, the number of times a patient woke up at night. A significant correlation between the degree of light/darkness in the bedroom could not be found. Likewise, no correlation could be found between breast cancer and switching on the light after waking up at night.

Melatonin is released at night and is produced by the epiphysis. Its release starts about $2 \mathrm{~h}$ before bedtime, reaches its peak 2 to $3 \mathrm{~h}$ after falling asleep and falls again with waking up 5. Melatonin is called the "hormone of darkness"; its release is suppressed by light. Experimental studies indicate the antineoplastic effect of melatonin due to several mechanisms: antioxitant, antimitotic, modulation capability of the immune system and of the lipid metabolism. Melatonin seems to be involved in the regulation of tumours. Moreover, melatonin blocks the estrogen receptors and influences the enzyme aromatase, which has an impact on the production of estradiol. While many studies show a relation between a reduced release of melatonin and night shifts, the evidence for the connection between sleep duration and the release of melatonin is still unclear. Because of this connection, shift work at night is considered a potential risk factor within the context of public health [7]. Consequently, improving the sleep quality of shift workers, i.e. reducing the frequency of waking up during sleep, could be an important preventive measure against severe insomnia [8] as well as against melatonin deficiency.

Light exposure at night, interruptions of the sleep-wakerhythm and resulting interruptions of the melatonin production are factors which are highly likely to contribute to a better understanding of the causes of breast cancer. Changes in the melatonin level cause changes in the level of sex hormones in the blood. This in turn increases the risk of hormone-induced diseases including breast carcinoma. Several international studies show an increased presence of breast cancer in night nurses. Therefore, it is recommendable to offer them the opportunity for regular preventive medical check-ups because they belong to a risk group for breast cancer [9].

In a prospective study on 23,995 Japanese women, a correlation was found between short sleeping times and an increased risk for breast cancer. The multivariate hazard ratio of women who slept less than $6 \mathrm{~h}$ was $1.62(95 \%$,
Fig. 1 Different pathophysiological mechanisms, behavioural and environmental factors that contribute to the occurrence of breast cancer in shift worker

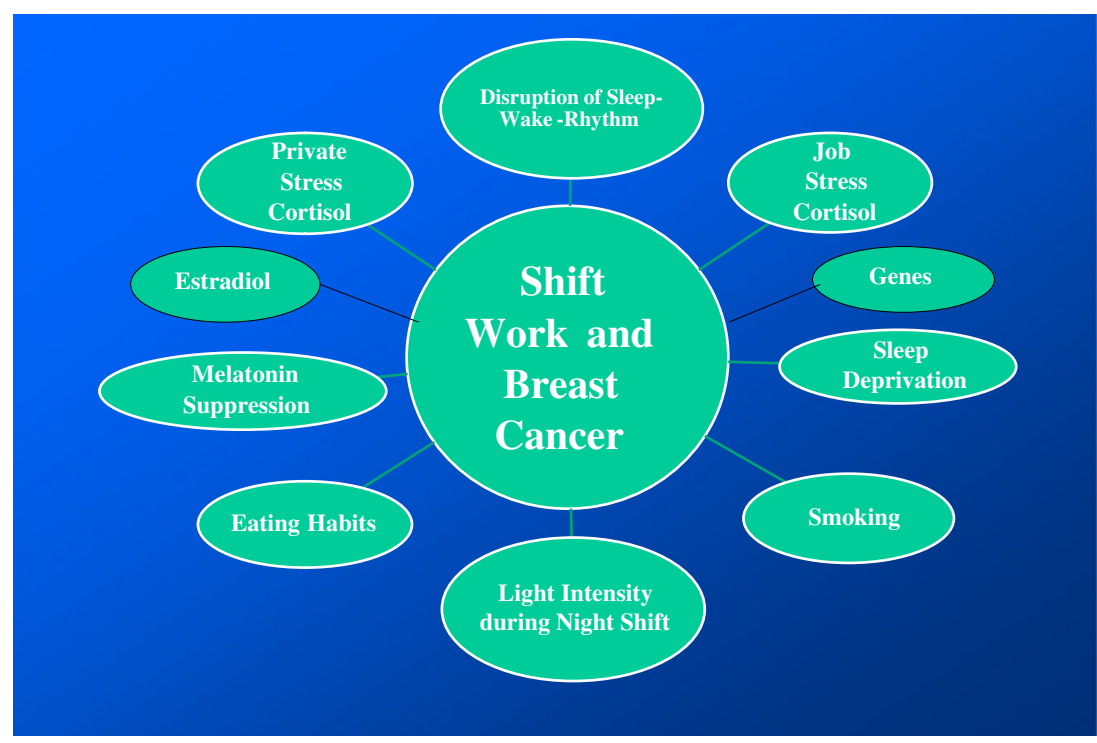


confidence interval: $1.05-2.50, \mathrm{p}$ for trend $=0.03$ ) [10]. The results of this study confirm the need to recommend the implementation of preventive sleep education courses.

Sleep deprivation, circadian disruption and clock genes

Sixty percent up to $85 \%$ of shift workers suffer from sleep disturbances [11, 12]. The sleep of shift workers is characterised by problems to fall asleep and to sleep through. Altogether, shift workers get less sleep than people working during the day $[13,14]$. As a result, they suffer from a sleep deficit [15]. A sleep deficit in itself impacts on the release of sex hormones: women with a sleep duration of under $8 \mathrm{~h}$ have an FSH hormone level which is $20 \%$ lower than that of women who sleep longer [16]. The interruption of the sleep-wake-rhythm as well as of circadian rhythms in women is closely connected to the interruption of the reproductive functions [3, 17]. Women doing shift work report irregular menstrual cycles and changes in the duration of their period and complain about frequent period pain as well as about changes in the amount of menstrual blood [18]. Also, with regard to cortisol, there are changes or conspicuous pathologic circadian profiles in the cortisol release in patients with breast cancer or ovarian cancer [19].

Shift workers often display symptoms of an immune suppression and have an increased risk for the development of cancer. There is an interaction between sleep and the immune system, also independent of the release of melatonin. Sleeping disorders may weaken the immune system and stimulate the cancer-cytogenesis. The studies show a correlation between a shortened sleep duration at night and an increased risk of breast cancer. Good sleep and continuous darkness during sleep time might become endogenous preventive mechanisms for cancer [20].

Shift work, jet lag and sleep deficits can change the rhythm of reproduction and of the expression of so-called clock genes. The expression of the clock genes was found in $\mathrm{SCN}, \mathrm{GnRH}$ neurons and female reproductive tissue. Estrogen likewise impacts on the expression of genes in other types of tissue. Moreover, estrogen exerts an influence on bodily activity and body temperature. Women also display other reproductive rhythms which are independent of the light/darkness influence. The release of the LH hormone, for instance, shows an individual cycle which occurs independent of the light-darkness-rhythm. The Master clock is located in the cells of the SCN and influences the clock genes in other organs which are responsible for reproduction. The clock genes in the SCN have their own rhythm and influence the rhythm of a woman's reproductive organs. The PER2 genes have their own rhythm with the peak at $4 \mathrm{~h}$ after switching-off the light in the evening. Any changes in the light-darknesscycle thus cause changes in the rhythms of all reproductive organs. SCN, ovarias and the womb are synchronised as far as the release of hormones is concerned. From experiments with mice it is known that SCN adapts most quickly to a changed light-darkness-rhythm, whereas other organs such as liver, lungs and muscles need six times longer to adapt to the new rhythm. Circadian disruption is a risk factor for breast cancer. Genes which are responsible for the circadian rhythm also regulate other circadian rhythms in the body including cell proliferation, cell cycles and apoptosis. Mutations in the circadian genes can contribute to the deregulation of these processes and thus to the development of tumours. Simultaneously, the mutation of circadian genes can be measured as a marker for the predisposition for cancer. Circadian genes such as, for instance, Per3 genotype might be used as biomarkers for breast cancer in the future $[3,21]$.

\section{Shift work and chronotype}

Work at unusual times leads to hyperarousal or causes increased physical and psychological stress. Late types suffer from more stress when they have to work on the morning shift, whereas early types suffer from more stress when they have to work at night. The greater the sleep deficit, the higher the stress on a person. The higher the stress, the higher the risk of cancer. At the same time, we know that late types smoke more and consume more alcohol. Thus, shift work per se does not constitute the sole factor for an increased presence of breast cancer. Rather, the adaptability of the individual chronotype to a specific shift as well as additional risk factors and, finally, the stress a person is under, play an important role [22].

While evening types have difficulties in going to bed earlier at night while working the morning shift, morning types experience difficulties in sleeping during the day while working the night shift. This means that morning types suffer from a sleep deficit during night shifts while evening types suffer from a sleep deficit during work on the morning shift [23].

A person's basic type is the most important protector and predictor for their adaptability to shift work. After work on the morning shift, early types sleep longer and better. Similarly, late types sleep longer and better after work on the night shift [24].

The individual chronotype can be a useful predictor for the adaptability to shift work and changed sleep-wake cycles. Girls with a family history for breast cancer should not choose professions which are connected with work in rotating shifts. 
Models for sleep education courses for shift workers

Shift workers rarely receive on-the-job training to help them cope with the rigours of working rotating shifts.

Since 1980, the NASA Ames Fatigue Countermeasures Program has examined fatigue-related issues and developed countermeasures, thereby recommending education, training and on-board crew rest facilities for flight personnel [25].

Some training programmes covered many different topics, such as circadian rhythms, sleep disorders, the impact of shift work on family and social life, alertness strategies, safe driving, nutrition, physical activity, coping with stress and experiences of other companies with new shift systems [26].

Knauth and Hornberger recommend, next to the education of managers, also a change in the organisation of shift systems as well as artificial light as part of the set of preventive and compensatory measures for the improvement of the health of shift workers [27].

Circadian Technologies Inc. (CIRCADIAN) is an international consulting firm that, for over 20 years, has helped employees cope better with shift work while simultaneously ensuring that employers can reduce costs and maximise profits. In a report by Circadian, five cost key areas were identified that should be optimised with regard to employment on shift work: productivity, turnover, absenteeism, accidents and health care costs. According to Circadian's research, the estimated costs which result from nonoptimised shift work are approximately $\$ 206$ billion/year or $\$ 8600$ per shift worker/year based on 24 million shift workers.

Circadian organised life style trainings for 600 shift workers and their families. One training consisted of education units that lasted for $4 \mathrm{~h}$ and included techniques for the improvement of sleep quality, fatigue management, enhancement of social skills activities and detailed information on circadian disruption.

The result was impressive; first of all, an extension of the sleep duration at daytime after night work was registered $(5.8 \mathrm{~h}$ after the training as compared to $4.8 \mathrm{~h}$ before the training). The gastrointestinal index as a marker for digestion problems dropped from a score of 17.9 to 13.6 indicating a significant reduction of gastrointestinal symptoms.

In another survey including 550 managers of companies operating at extended hours, a significant economic effect was found: there were significantly lower costs as a result of lower turnover (7.6\% vs. 11.4\%) or $\$ 952$ per worker/ year. By way of reducing absenteeism, companies saved \$ 940 per shift worker/year which suggests savings of $\$ 1,892$ per employee/year [28].

A pre- and post-training study by Circadian showed an improvement in health and fatigue indices and an increase in day-time sleep length. Companies that provide life-style trainings for shift workers also have lower rates of absenteeism and turnover than companies that do not provide such trainings [14].

The authors of this paper (Richter et al.) recommend sleep training courses which are conducted as a series of three seminars lasting $120 \mathrm{~min}$. each. In addition to that, one 2-hour seminar should be offered for management staff (Fig. 2).

The time investment for shift workers amounts to $6 \mathrm{~h}$ for the complete course. There should be about 15-25 participants per education group. By way of sleep logs for each participant, a personal sleep profile can be compiled; this, in turn, allows for a personalised approach to the sleep-wake profile and recommendations for the improvement of the sleep quality of every person in the course.

\section{Conclusions and recommendations}

In view of current data, it may be considered a fact that shift work represents a risk factor for the development of breast cancer. In this context, not only shift work in itself constitutes a risk but also many other factors which are related to the disruption of the sleep-wake rhythm such as a lack of melatonin, the disruption of the circadian rhythms of the body on a molecular level, disruptions of the circadian rhythm of the release of stress hormones such as cortisol and of sex hormones such as estradiol. Likewise, increased stress due to sleep deprivation, the coordination of shift work with family life, irregular meals, a lack of physical exercise and smoking contribute to a heightened risk.

Therefore, it seems recommendable to come up with measures by means of which steps for health promotion or, respectively, for primary prevention or prediction can be taken already in advance.

\section{Health promotion}

Further studies are to demonstrate or to examine whether shift work increases the development of breast cancer in women with a positive family history. If shift work does

\section{IDEAL TIMEFRAME FOR THE SEMINARS}

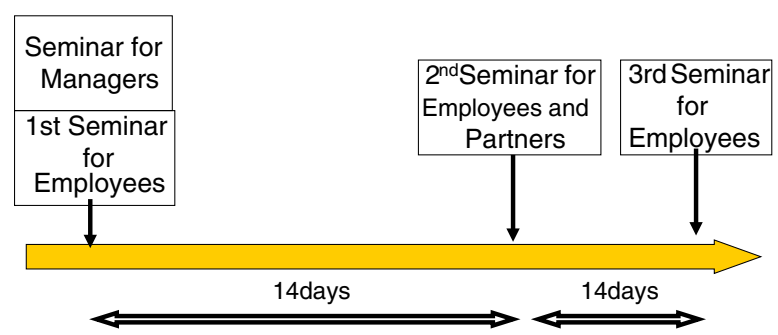

Fig. 2 Ideal timeframe for the seminars 
Fig. 3 Recommendations for health promotion and primary prevention of breast cancer in shift worker

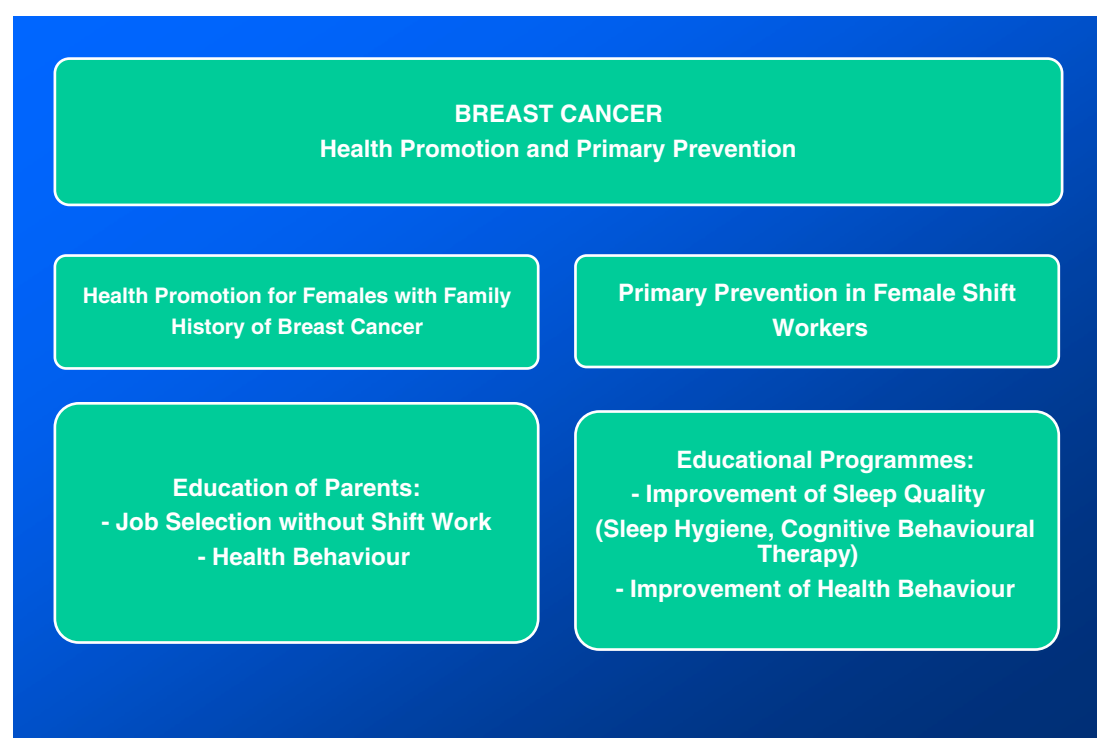

represent an additional increased risk for the development of breast cancer in women with a positive family history, this might have consequences with regard to the professional orientation of such women. It would mean that parents of girls with a positive family history should be counselled so as to be able to assist their daughters in the choice of a future career. The girls should be advised not to choose a profession related with shift work. In this process, the counselling activity could be taken over by health insurances.

\section{Prediction}

The knowledge on the adaptability of a shift worker to the changing sleep-wake activity can be used as a predictor for choosing work in morning versus rotating shift. Ideally, morning chronotypes should work in day shift and evening types in night or rotating shift. Besides, specific biomarkers should be assessed regularly.

\section{Primary prevention}

Women on shift work should attend educational courses on sleep in order to prevent insomniac disorders as well as sleep deficits.

For this purpose, such sleep education courses should be offered regularly by employers in the companies.

The corresponding contents should include topics from sleep hygiene, cognitive behavioural therapy and relaxation techniques.

Even though it is at present by no means confirmed that shift work contributes to the development of cancer, it is nevertheless requested that current findings from occupational medicine as well as from biology and the occupational sciences be taken into consideration (Fig. 3).

\section{Outlook}

Sleep education courses for female shift workers can reduce the costs for the health system, medication costs and costs for companies because of reduced turnover and absenteeism and fewer accidents. Moreover, the courses can lead to higher productivity and the prevention of various diseases.

If we think of the future which, by now, has already become the present, the following will happen: already in childhood, we will, on the basis of genetic typing and biomarkers, know which health risks a person carries. Starting from these risk factors, preventive measures will be taken.

Accordingly, a girl with an increased risk for breast cancer will most probably not choose to enter a Bachelor programme for nursing because shift work further increases the risk of breast cancer. Predicative medicine will be closely connected with prevention.

At present, however, a lot can already be done to promote and maintain the health of employees on shift work by way of trainings. The prediction of sleepassociated health disorders, the prevention of sleep disorders and a personalised approach to changes in the circadian rhythm can be effective measures for the improvement of the general health status of a shift worker, for the prevention of some diseases including breast cancer, for the enhancement of productivity and the reduction of absenteeism.

Such measures must primarily be initiated and supported by executives, though. 


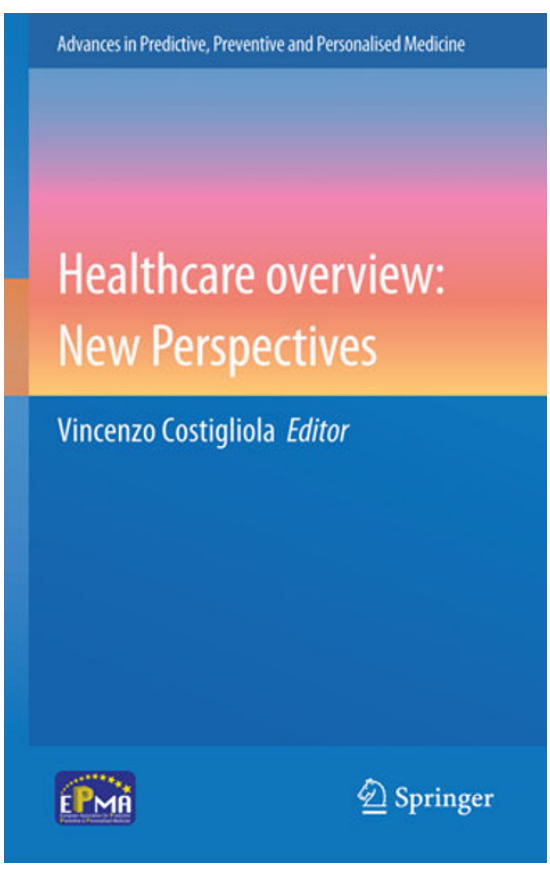

Fig. 4 New volume in the book series "Advances in PPPM" proposed as the didactic material for PPPM-related courses and programmes

The authors of this paper recommend the corresponding volume with detailed didactic material for sleep education courses for shift workers, which can be used for education of professional groups/companies. The volume will be published in the book series "Advances in PPPM" that will be released by Springer in collaboration with EPMA (starting in 2012, Fig. 4).

\section{References}

1. Hansen J. Risk of breast cancer after night- and shift work: current evidence and ongoing studies in Denmark. Cancer Causes Control. 2006;17(4):531-7.

2. Erren TC, Morfeld P, Stork J, Knauth P, von Mülmann MJ, Breitstadt R, et al. Shift work, chronodisruption and cancer?-The IARC 2007 challenge for research and prevention and 10 theses from the Cologne Colloquium 2008. Scand J Work Environ Health. 2009;35(1):74-9.

3. Schernhammer ES, Laden F, Speizer FE, Willett WC, Hunter DJ, Kawachi I, et al. Rotating night shifts and risk of breast cancer in women participating in the nurses' health study. J Natl Cancer Inst. 2001;93(20):1563-8.

4. Megdal SP, Kroenke CH, Laden F, Pukkala E, Schernhammer ES. Night work and breast cancer risk: a systematic review and metaanalysis. Eur J Cancer. 2005;41:2023-32.

5. Erren TC, Falaturi P, Morfeld P, Knauth P, Reiter RJ, Piekarski C. Schichtarbeit und Krebs. Dtsch Arztebl Int. 2010;107(38):657-62.

6. Davis S, Mirick DK. Night shift work, light at night, and risk of breast cancer. J Natl Cancer Inst. 2001;93(20):1557-62.
7. Viswanathan AN, Schernhammer ES. Circulating melatonin and the risk of breast and endometrial cancer in women. Cancer Lett. 2009;281(1):1-7.

8. Crönlein T, Zulley J. The options available in cognitive behavioral therapy to reduce the right of insomnia. EPMA J. 2011; doi:10.1007/s13167-011-0095-9.

9. Franzese E, Nigri G. Night work as a possible risk factor for breast cancer in nurses. Correlation between the onset of tumors and alterations in blood melatonin levels. Prof Inferm. 2007;60 (2):89-93.

10. Kakizaki M, Kuriyama S, Sone T, Ohmori-Matsuda K, Hozawa A, Nakaya N, et al. Sleep duration and the risk of breast cancer: the Ohsaki Cohort Study. Br J Cancer. 2008;99(9):1502-5.

11. Stevens RG. Working against our endogenous circadian clock: breast cancer and electric lighting in the modern world. Mutat Res. 2009;680(1-2):106-8.

12. Czeisler CA, Johnson MP, Duffy JF, Brown EN, Ronda JM, Kronauer RE. Exposure to bright light and darkness to treat physiologic maladaptation to night work. N Engl J Med. 1990;322 (18):1253-9.

13. Czeisler CA, Allan JS, Strogatz SH, Ronda JM, Sanchez R, Rios $\mathrm{CD}$, et al. Bright light resets the human circadian pacemaker independent of the timing of the sleep-wake cycle. Science. 1986;233(4764):667-71.

14. Fröberg JE, Karlsson CG, Levi L, Lidberg L. Psychobiological circadian rhythms during a 72 hour vigil. Försvarsmedicin. 1975; II:192-201.

15. Wilkinson RT. How fast should the night shift rotate? Ergonomics. 1992;35(12):1425-46.

16. Colligan MJ, Tepas DI. The stress of hours of work. Am Ind Hyg Assoc J. 1986;47(11):686-95.

17. Mahoney MM. Shift work, jet lag, and female reproduction. Int J Endocrinol. 2010;2010:813764.

18. Chung SA, Wolf TK, Shapiro CM. Sleep and health consequences of shift work in women. J Womens Health (Larchmt). 2009;18 (7):965-77.

19. Labyak S, Lava S, Turek F, Zee P. Effects of shiftwork on sleep and menstrual function in nurses. Health Care Women Int. 2002;23(6-7):703-14.

20. Blask DE. Melatonin, sleep disturbance and cancer risk. Sleep Med Rev. 2009;13(4):257-64.

21. Touzet S, Rabilloud M, Boehringer H, Barranco E, Ecochard R. Relationship between sleep and secretion of gonadotropin and ovarian hormones in women with normal cycles. Fertil Steril. 2002;77(4):738-44.

22. Akerstedt T, Kecklund G, Gillberg M. Sleep and sleepiness in relation to stress and displaced work hours. Physiol Behav. 2007;92(1-2):250-5.

23. Juda M. The importance of chronotype in shift work research. In: Inaugural-Dissertation. München, 18.3.2010.

24. Crowley SJ, Lee C, Tseng CY, Fogg LF, Eastman C. Combinations of bright light, scheduled dark, sunglasses, and melatonin to facilitate circadian entrainment to night shift work. J Biol Rhythms. 2003;18(6):513-23.

25. Rosekind M, Gander H, Gregory K, Smith R, Miller D, Oyung R, et al. Managing fatigue in operational settings 2: an integrated approach. Behav Med. 1996;21:166-70.

26. Furuki K, Kitahara K, Momota Y, Higashi T. Guidelines for the health care management of shift workers on the night shift in Japan. In: Hornberger S, Knauth P, Costa G, Folkard S, editors. Shift work in the 21st century. Frankfurt: Peter Lang; 2000. p. 389-92.

27. Knauth P, Hornberger S. Preventive and compensatory measures for shift workers. Occup Med. 2003;53:109-16.

28. CIRCADIAN's shiftworks practices 2004 survey. A survey of 600 employers of shiftworkers, 2004. 